\title{
Pembangkit Pulsa Pemicu Berdasarkan Detektor Persilangan Nol yang Diperoleh dari Analog to Digital Converter dan Interrupt
}

\author{
Darmawan Utomo \\ Program Studi Sistem Komputer, \\ Fakultas Teknik Elektronika dan Komputer, \\ Universitas Kristen Satya Wacana, Salatiga \\ darmawan@staff.uksw.edu
}

\begin{abstract}
Ringkasan
Pada makalah ini diusulkan sebuah teknik yang memanfaatkan port dari mikrokontroler sebagai pembangkit pulsa pemicu berdasarkan detektor persilangan nol dengan cara menganalisa transisi nilai-nilai analog to digital converter dan teknik interrupt. Percobaan dilaksanakan dengan sumber tegangan ac 12 volt yang diseri dengan resistor $20 \mathrm{k} \Omega$ lalu dihubungkan dengan masukan analog dan interrupt dari arduino UNO. Untuk transisi dari rendah ke tinggi, pada teknik adc dan interrupt masing-masing tertunda $+0,5$ ms terhadap nilai nol. Pada teknik adc dari tinggi ke rendah, nilai nol terdeteksi 0,3 ms sebelum kejadian sedangkan pada interrupt $+0,25$ ms setelah 0 volt terlewati.
\end{abstract}

Kata kunci:analog to digital converter, zero crossing, interrupt, sudut-picu, mikrokontroler

\section{Pendahuluan}

Pada rangkaian pengubah tegangan yang dapat diatur dari sumber ac ke dc, baik yang fasa tunggal maupun tiga, dibutuhkan pemicu yang didasarkan pada persilangan tegangan nol [1]. Persilangan ini menjadi acuan kapan sudut picu harus diberikan. Hasil deteksi persilangan yang terlambat/setelah persilangan, mengakibatkan sudut picu kecil tidak dapat ditargetkan. Sebaliknya, jika terlalu cepat/sebelum persilangan, dibutuhkan waktu tunda sebagai kompensasinya.

Untuk menghasilkan persilangan tegangan nol diperlukan Detektor Persilangan Nol (DPN). Dalam sistem berbasis mikrokontroler, DPN dapat direalisasikan dengan untai eksternal maupun secara internal. Ada dua macam masukan yang bisa digunakan, lewat pin I/O, interrupt, dan ADC. Teknik DPN dengan pin I/O dan interrupt memanfaatkan kondisi dari logika rendah $(\mathrm{L})$, tinggi $(\mathrm{H})$, dan transisinya. 


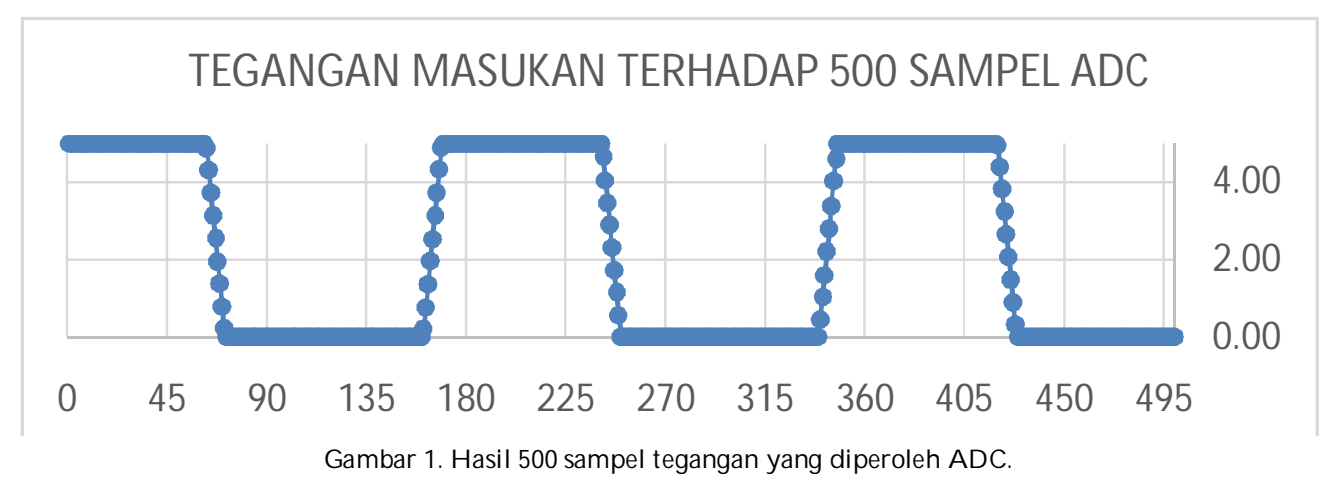

Dua teknik ini memiliki peluang adanya kesalahan akibat kejadian luar seperti munculnya tegangan sesaat yang dapat mengganggu picuan. Teknik menunda dan membaca kondisi pin beberapa kali biasa diterapkan untuk mengatasi gangguan ini. Kelemahan lain adalah deteksi nol muncul setelah titik persilangan nol pada transisi rendah ke tinggi, dan mendekati nol dari transisi tinggi ke rendah. Hal ini mengakibatkan hasil persilangannya tidak bisa segera dimanfaatkan untuk memicu karena menunggu siklus berikutnya.

Pada teknik ADC, sinyal masukan disampel puluhan kali di atas frekuensi sumber ac. Gambar 1 adalah salah satu hasil pengambilan 500 sampel tegangan 12 volt ac. Ada empat macam hasilnya yaitu, kondisi aras rendah, kondisi transisi ke tinggi, kondisi aras tinggi, dan kondisi transisi ke rendah. Kondisi aras rendah diperoleh karena tegangan masukan lebih rendah dari GND-0,5V sedangkan kondisi aras tinggi diperoleh karena tegangan masukan lebih tinggi dari VCC $+0,5 \mathrm{~V}$. Kondisi-kondisi transisi diperoleh saat tegangan bernilai di antara $0 \mathrm{~V}$ hingga $5 \mathrm{~V}$.

Dari Gambar 1 tampak jelas bahwa transisi dari aras tinggi ke rendah atau dari aras rendah ke tinggi memiliki banyak hasil adc yang dapat digunakan untuk menentukan sebelum dan setelah terjadinya persilangan nol.

\subsection{Kajian Pustaka}

Salah satu teknik secara eksternal adalah dengan menggunakan optocoupler, dimana saat mendekati persilangan nol, diode tidak memancarkan cahaya sehingga transistor masuk pada fase cut-off atau dari tegangan nol yang melalui diode menuju bias maju yang membuat transistor masuk ke fase saturasi [2]. Keluaran dari transistor biasanya digandeng dengan rangkaian darlington untuk memberikan tanggapan yang lebih cepat. Cara lain adalah dengan menggunakan komparatorop-amp dengan tegangan pembanding yang dapat diatur. Cara kerjanya adalah saat mencapai tegangan nol dari tegangan positif komparator lebih tinggi dari tegangan pembanding diatur untuk menghasilkan keluaran positif. Keluaran ini digunakan untuk menggerakkan monostabil sebagai tanda adanya persilangan nol [3].

DPN dapat juga dibuat berdasarkan respon terhadap pin-pin masukan yang terdapat di mikrokontroler. Pin-pin yang dapat digunakan adalah pin masukan, interrupt, dan pin analog. Sebelum masuk ke masing-masing pin, sinyal ac/dc harus melewati pengondisi sinyal supaya tidak melewati batas masukan maksimum yang diizinkan. Secara umum, pin-pin masukan dari mikrokontroler sudah mendapat pengaman dua buah diode clamping. Fungsinya adalah jika ada tegangan yang lebih besar dari pada VCC $+0,5 \mathrm{~V}$ atau lebih kecil dari GND-0,5V akan dipaksa menjadi VCC+0,5V atau GND-0,5V. Arus 
maksimal yang direkomendasikan adalah $1 \mathrm{~mA}$, jika lebih dimungkinkan merusak diode clamping[4].

Setelah melewati pengondisi sinyal, jalur ini dapat dihubungkan dengan pin-pin yang terdapat di mikrokontroler. Teknik yang umum digunakan untuk mendeteksi melalui jalur pin masukan adalah dengan mendeteksi nilai rendah (nol) atau hinggi (satu) secara terus-menerus. Jika ditemukan kondisi yang diinginkan misalnya nol, yang berarti ditemukan silang nol, maka mikrokontroler dapat menunda selama sudut picu yang diinginkan, baru kemudian memberikan picuan ke bagian penggerak (driver). Teknik ini memaksa mikrokontroler bekerja terus-menerus mengawasi pin ini sehingga tidak dapat mengerjakan pekerjaan lain. Kelemahan lain adalah mikrokontroler sangat responsif dengan gangguan tegangan sesaat yang dapat menyebabkan kesalahan sudut picu.

Secara umum teknik menggunakan pin interrupt hampir sama dengan deteksi melalui pin masukan. Perbedaan utama terletak pada mikrokontroler masih bisa melakukan pekerjaan lain selama menunggu adanya DPN. Saat munculnya interupsi, rutin pelayanan interrupt dipanggil. Rutin ini dapat digunakan untuk mengaktifkan fungsi penunda picuan sesuai dengan parameter yang diinginkan.

\section{Perancangan}

\subsection{Diagram Rancangan}

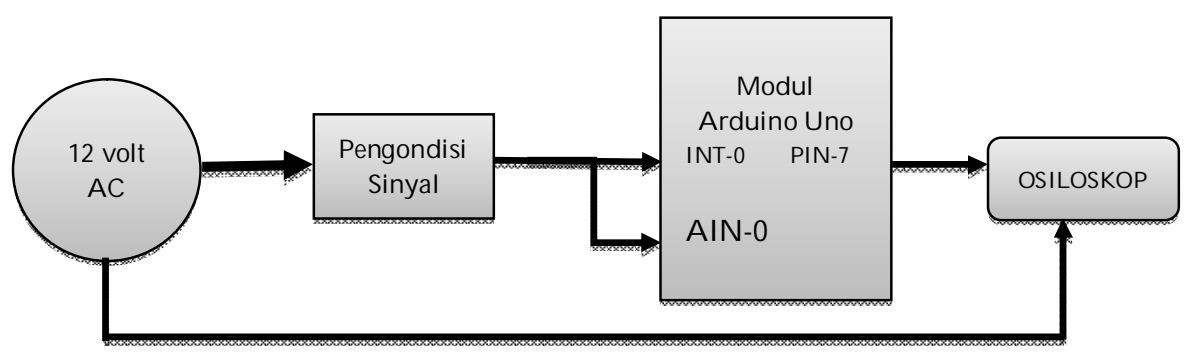

Gambar 2. Diagram perancangan detector persilangan nol melalui INT dan ADC.

Pada Gambar 2 ditunjukkan sebuah perancangan pengujian detector persilangan nol. Pembangkit gelombang ac diperoleh dari sekunder trafo 12 Vac. Rangkaian ini sanggup untuk menerima masukan hingga 20 Vac berdasarkan kemampuan diode clamping melewatkan $1 \mathrm{~mA}$. Mikrokontroler [4]. Tegangan dari trafo dihubungkan dengan pengondisi sinyal seperti yang ditunjukkan pada Gambar 3. Dioda clamping tambahan dipergunakan sebagai pengaman tambahan. Keluaran dari pengondisi sinyal dihubungkan dengan pin-2 (INT-0) dari modul Arduino Uno untuk percobaan DPN dengan interrupt, dan pin-A0 untuk percobaan DPN dengan ADC. Sumber daya untuk modul Arduino dan monitor evaluasi melalui data serial menggunakan jalur USB dari PC, dan aplikasi Arduino Serial Monitor. 


\subsection{Kode Program}

Arduino diberi dua macam kode untuk interrupt (Kode 1) dan adc (Kode 2). Masingmasing kode dibuatkan variasi untuk kondisi dari rendah ke tinggi dan dari tinggi ke rendah. Pada Kode interrupt, detektor nol kondisi tinggi ke rendah direalisasikan dengan membuat kode bagian attachInterrupt(0, ISR0, FALLING); dan rendah ke tinggi dengan instruksi attachInterrupt(0, ISR0, RISING); Jalur pin 2 dari Arduino dihubungkan dengan INT-0 seperti yang diperlihatkan pada Gambar 3. Untuk mengamati hasil eksperimen, osiloskop saluaran 1 ( $\mathrm{CH}-1)$ dihubungkan dengan $12 \mathrm{Vac}$, dan saluran 2 (CH-2) dihubungkan dengan pin-7 Arduino Uno. Aksi variasi keluaran dapat dimodifikasi untuk pin yang berbeda baik yang satu fasa maupun tiga fasa atau variasi lainnya.

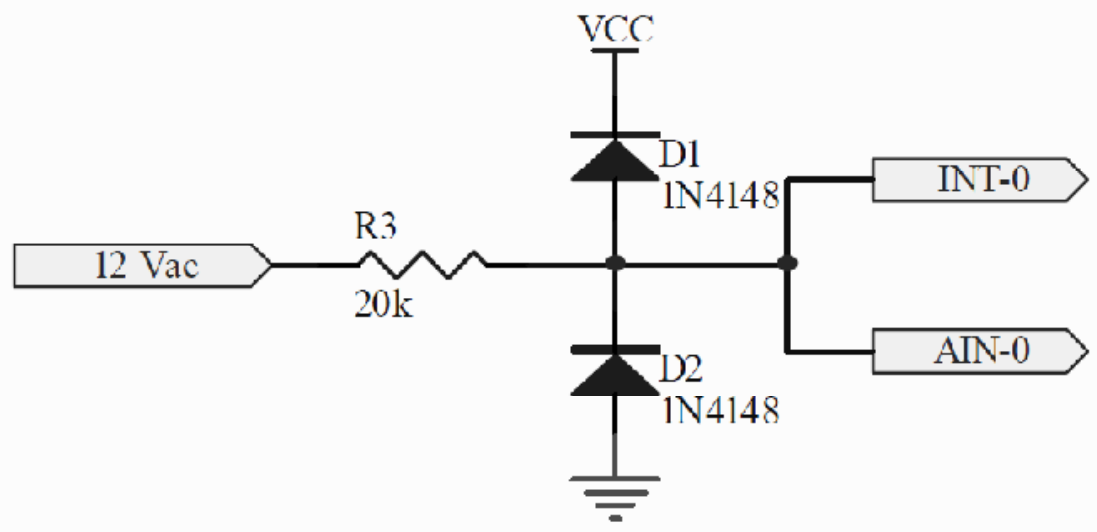

Gambar 3. Untai Pengondisi masukan 12Vac supaya tidak melebihi syarat masukan dari pin INT-0 dan AIN-0 dari Modul Arduino Uno.

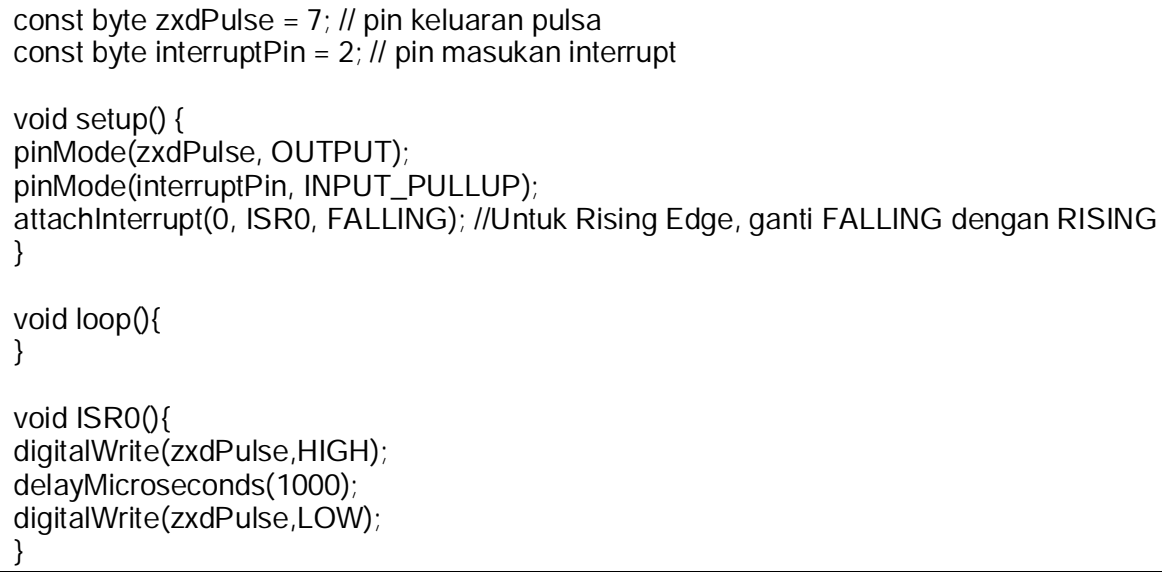

Kode 1. DetektorNoldenganteknik interrupt danpembangkitpulsapicuselama $1 \mathrm{~ms}$

Kode 2 adalah kode percobaan untuk mendeteksi DPN dengan adc, detector persilangan nol tinggi ke rendah dengan membuat kode bagian checkZXD_fall(); dan rendah ke tinggi dengan instruksi checkZXD_rise(); Masukan adc diperoleh dari pin-A0, dan keluaran pulsanya dihasilkan dari pin-7. Pada teknik adc diperlukan waktu untuk mengambil data dan menganalisa apakah sinyal telah melewati batas rendah ke tinggi atau tinggi kerendah atau belum. Transisi rendah ke tinggi dapat ditentukan dari nilai 
Pembangkit Pulsa Pemicu Berdasarkan Detektor Persilangan Nol yang Diperoleh dari Analog to Digital Converter dan Interrupt

Darmawan Utomo

adc awal nol dan berikutnya harus lebih dari nol. Sedangkan transisi tinggi $(\mathrm{H})$ ke rendah (L) ditentukan dari awal 1023 dan akhir harus kurang dari 1023.

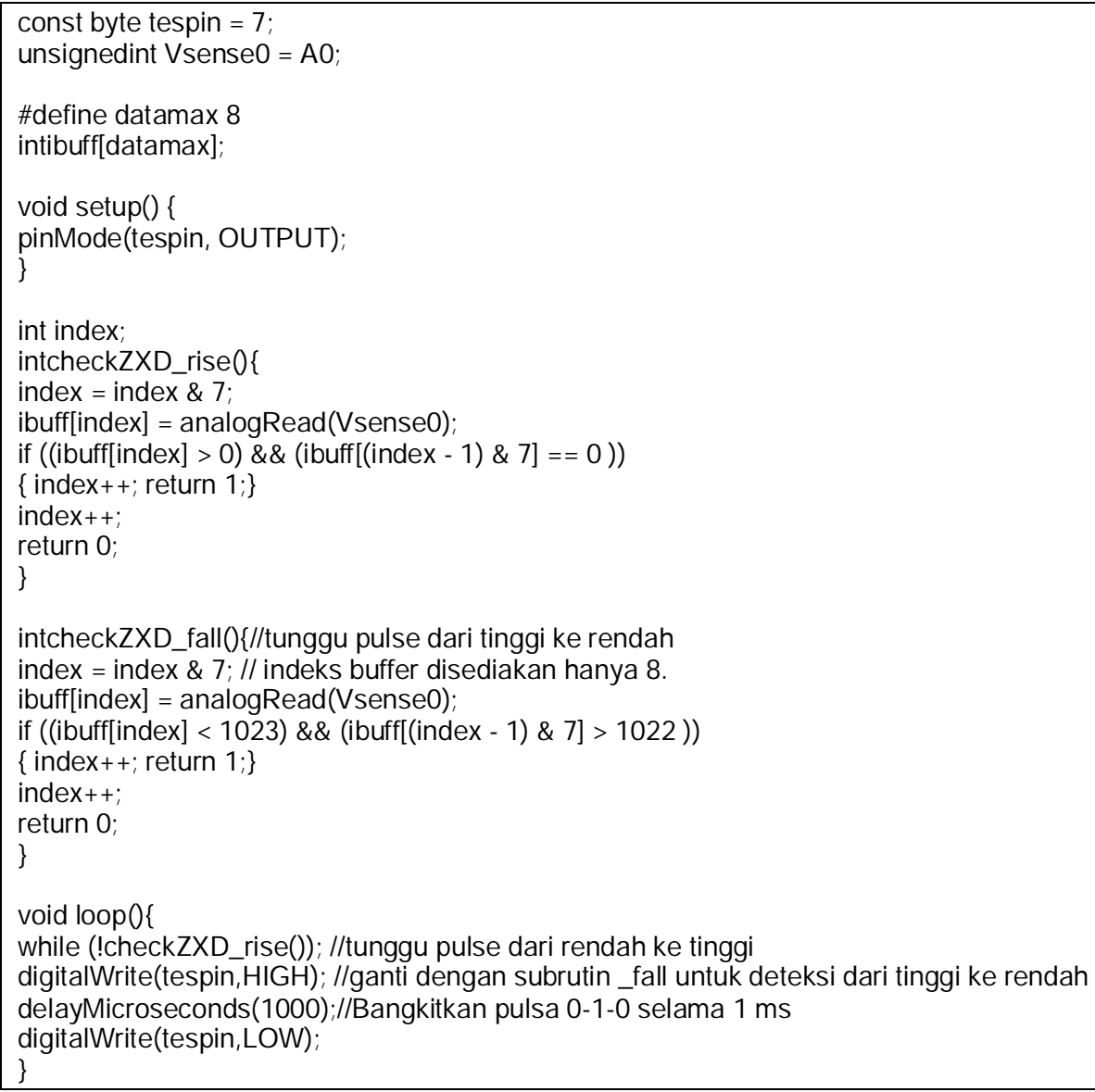

Kode 2. Detektor Nol dengan teknik adc dan pembangkit pulsa picu selama $1 \mathrm{~ms}$.

\section{Langkah dan HasilPercobaan}

\subsection{Langkah Percobaan}

Langkah percobaan dari model ini adalah sebagai berikut:

1. Siapkan rangkaian dari sumber tegangan ac, pengondisi sinyal, Arduino Uno, dan osiloskop 2 saluran.

2. Unggah Kode program 2 keArduino untuk pengujian DPN melalui analog input A0.

3. Atur osiloskop sinkron dengan masukan $\mathrm{CH} 1$ (tegangan 12Vac), 5V/Div, dan 2,5ms/Div.

4. Simpan hasilnya (a.1), dan ubah T/Div-nya menjadi $1 \mathrm{~ms}$, dan simpan hasilnya (a.2).

5. Modifikasi Kode program 2 dari deteksi while (!checkZXD_rise()); menjadi while (!checkZXD_fall());

6. Unggah Kode program 2 hasil modifikasi. 
7. Atur osiloskop sinkron dengan masukan $\mathrm{CH} 1$ (tegangan $12 \mathrm{Vac}$ ), 5V/Div, dan 2,5ms/Div.

8. Simpan hasilnya (a.3), dan ubah T/Div-nya menjadi $1 \mathrm{~ms}$, dan simpan hasilnya (a.4).

9. Unggah Kode program 1 ke Arduino untuk pengujian DPN melalui INT-0.

10. Atur osiloskop sinkron dengan masukan $\mathrm{CH} 1$ (tegangan 12Vac), 5V/Div, dan $5 \mathrm{~ms}$ /Div.

11. Simpan hasilnya (b.1), dan ubah T/Div-nya menjadi $1 \mathrm{~ms}$, dan simpan hasilnya (b.2).

12. Modifikasi Kode program 1 dari deteksi argument RISING ke FALLING.

13. Unggah Kode program 1 hasil modifikasi.

14. Atur osiloskop sinkron dengan masukan $\mathrm{CH} 1$ (tegangan 12Vac), 5V/Div, dan 2,5ms/Div.

15. Simpan hasilnya (b.3), dan ubah T/Div-nya menjadi 1ms, dan simpan hasilnya (b.4).

\subsection{Hasil Percobaan}

Gambar 4 mewakili teknik adc (a) dan interrupt (b). Hasil yang didapatkan diperoleh dari pemicuan yang disinkronkan dengan $\mathrm{CH}$ 1. Lebar pulsa diatur selama $1 \mathrm{~ms}$. Tampak Trig'd pada bagian atas osiloskop yang berarti bahwa pulsa picu yang dihasilkan selalusinkron dengan sumber 12 Vac.

4.a.1. adc $\mathrm{L} \rightarrow \mathrm{H}$

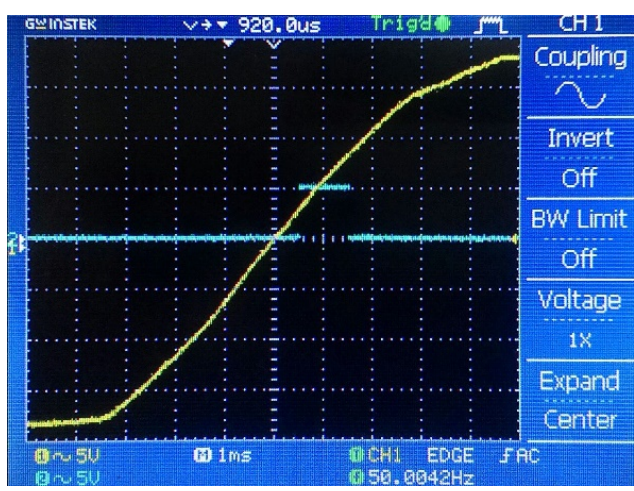

4.a.2. $\mathrm{AdcH} \rightarrow \mathrm{L}$

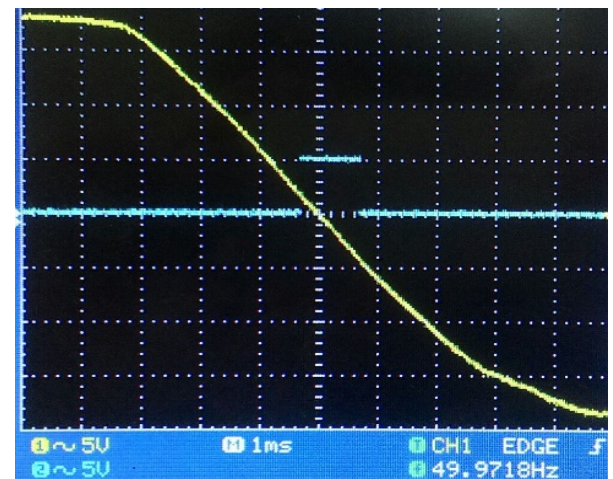

4.b.1. INT $\mathrm{L} \rightarrow \mathrm{H}$

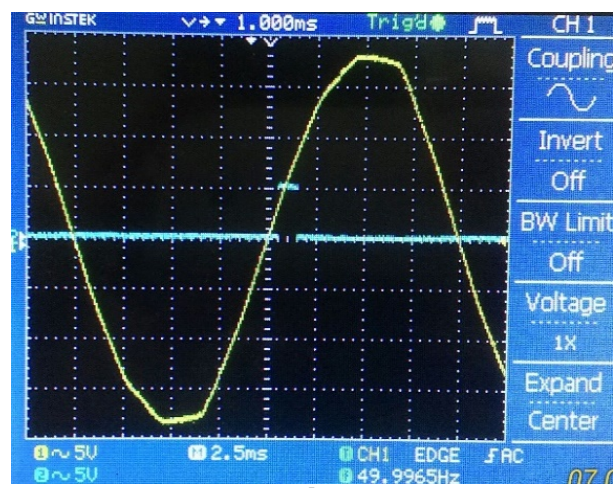

4.b.2. INT $\mathrm{H} \rightarrow \mathrm{L}$

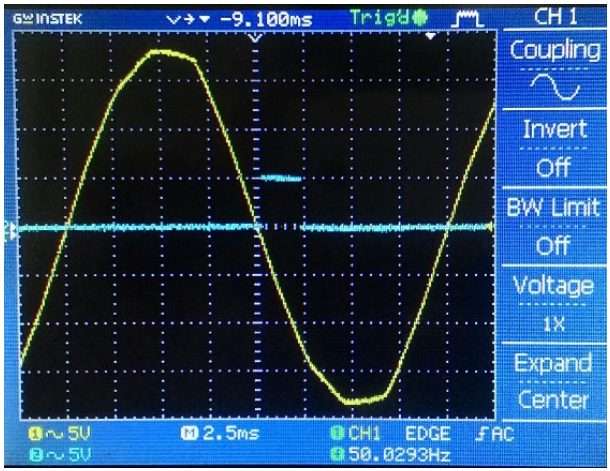

Gambar 4. Pulsa Picu dari teknik adc (a) dan teknik interrupt (b), dengan transisi rendah ke tinggi (1) dan transisi tinggi ke rendah (2). 
Pembangkit Pulsa Pemicu Berdasarkan Detektor Persilangan Nol yang Diperoleh dari Analog to Digital Converter dan Interrupt Darmawan Utomo

Tabel 1. Awal pulsa terhadap titik silang nol.

\begin{tabular}{|c|c|c|c|c|}
\hline JenisPercobaan & ADC $\mathrm{L} \rightarrow \mathrm{H}$ & ADC $\mathrm{H} \rightarrow \mathrm{L}$ & INT $\mathrm{L} \rightarrow \mathrm{H}$ & INT $\mathrm{H} \rightarrow \mathrm{L}$ \\
\hline $\begin{array}{c}\text { Waktu awal Pulsa } \\
\text { terhadap titik silang nol } \\
(\mathrm{ms})\end{array}$ & $+0,5$ & $-0,3$ & $+0,5$ & $+0,25$ \\
& & & & \\
\hline
\end{tabular}

Dari hasil pengamatan seperti yang diperlihatkan pada Tabel 1, dapat diprediksi bahwa ADC $\mathrm{L} \rightarrow \mathrm{H}$, INT $\mathrm{L} \rightarrow \mathrm{H}$, dan INT $\mathrm{H} \rightarrow \mathrm{L}$ menghasilkan tundaan terhadap persilangan nol karena untuk pindah keadaan selalu membutuhkan titik nol. Untuk ADC $\mathrm{H} \rightarrow \mathrm{L}$ tidak membutuhkan titik nol untuk mendeteksi transisi ke nol sehingga bisa lebih cepat $0,3 \mathrm{~ms}$ terhadap titik nol. Hal ini bisa dimanfaatkan untuk memperluas jangkauan picuan karena bisa dimulai sebelum titik nol.

\section{Kesimpulan}

Penggunaan titik nol sebagai acuan detector persilangan nol akan menghasilkan waktu tunda positif sebesar 0,5 ms baik untuk teknik ADC dan interrupt pada saat transisi dari kondisi rendah ke tinggi. Untuk transisi dari tinggi ke rendah, waktu tunda negative sebesar $0,3 \mathrm{~ms}$ diperoleh dengan menggunakan teknik ADC dan positif $0,25 \mathrm{~ms}$ dengan teknik interrupt.

\section{DaftarPustaka}

[1] Hart, D.W., “Power Electronics”, McGraw-Hill, 2011.

[2] Elektuur, "303 Circuits", U. Elektuur B.V., 1988.

[3] Texas Instruments, “LM393/D Rev.31”, Texas Instruments, 2016.

[4] Atmel, “AVR182: Zero Cross Detector”, Atmel Corp., 2016. 